\title{
The Issues and Realities of BRT Planning Initiatives in Developing Asian Cities
}

Moazzem Hossain, Transportation and Logistics Program

Malaysia University of Science and Technology (MUST)

\begin{abstract}
Successful Bus Rapid Transit (BRT) planning initiatives in Latin American cities involved complex interactions among stakeholders, politicians and planners. Asian cities under different geo-political settings may not be able to achieve successful BRT planning initiatives under similar circumstances. This paper reviews the recent mass transit planning initiatives, especially BRT planning initiatives, in Asian cities and identifies the issues and realities of such initiatives in different regions of Asia. The prospect, suitability and importance of BRT as a sustainable mass transit system for Asian cities are also discussed. Guidelines are suggested for probable successful BRT planning initiatives under different geo-political contexts of Asian cities.
\end{abstract}

\section{Introduction}

BRT has emerged as an economically self-reliant mass transit system with significant potential for budget-constrained developing cities. The successful BRT systems, particularly in Latin American cities, have evolved through broad-based participation of all the actors and fair distribution of costs, risks and benefits among the same (Ardila 2004; Wright 2005). Wright (2001) mentioned that Latin American busways show that the availability of capital is secondary to political and technical will. Patrick and William (2005) also emphasized the need for pub- 
lic-private partnership (PPP) in financing, implementing and operating successful BRT systems integrated with multi-modal transport networks. While such a broad participatory planning process has taken place under the umbrella of the powerful mayors of Latin American cities (Hook 2005; Ardila 2004), by tradition, mayors of most Asian cities do not enjoy that sort of power due to the bureaucratic central government influence and absence of proper city government structure, in many cases. Often, urban transport decision making involves multiple agencies such as ministries for communication, city mayors, city transport authorities, and sometimes even finance/prime ministries. While these are the top layer of decision makers, there is also a bottom layer of stakeholders such as transit operators, planners and civic groups. It is not easy to track a planning and decision making process in such a situation involving multiple parties. The case of BRT planning appears to be more intricate, as it needs a general acceptability among all parties because of the intrinsic characteristics of BRT system development. BRT systems need cooperation and participation from all quarters as successful BRT systems emerge from contributions of public-private partnership and collaboration. Hook (2004) mentioned that the relationship between BRT and regulatory and institutional reform is less understood, although it is one of the most important elements distinguishing BRT from normal busways. Even with all the advantages of BRT, such as low cost, flexibility and easy installation, it hardly generates any self-motivated interest group, as the system rarely allows favor to a particular party. So, the question now is, who would promote those advantages of BRT and work through the complex interactive roadmap of multi-agency planning tasks to ultimately see through the adoption of a comprehensive BRT system plan. This paper reviews the current mass transit planning initiatives of a few Asian cities in the light of the above issues. Recent institutional, political and planning dynamics in the cities are analyzed in detail. Finally, guidelines are suggested for the BRT planning process initiatives for Asian developing cities in the light of those experiences.

\section{Mass Transit Initiatives of Asian Cities}

Asia has almost 200 cities with populations over 1 million, including 98 cities in China and 35 in India (Singh 2005), two of the world's most populous countries. Most of these populations, especially the lower-middle to low income groups, are heavily dependent on public transportation. In the absence of an adequate public transportation supply, most of these cities' streets are crowded with two-wheelers and other motorized para-transits (Singh 2005; Hoque and Hossain 2005; Hossain 
et al. 2003; Hossain and McDonald 1998), which cannot substitute for a mass transit system appropriate to the demand volumes of these cities. Also, it is worth mentioning that some of the middle income cities, such as Kuala Lumpur, Bangkok, Beijing and Shanghai, are going through rapid motorization at an alarming rate (Townsend 2001; UN ESCAP 2005; Energy Foundation 2005). Although these cities invested heavily in road-based infrastructure, the rate of motorization always outpaces the supply of road network. Therefore, cities of both income ranges are facing the problems of congestion, safety, traffic-related air pollution, and excessive (80 to $90 \%$ in Asia) commercial energy consumption in the transport sectors (UNESCAP 2005). For example, approximately 60 percent of the Bangkok population suffers from throat irritation, apparently caused by air pollution; Dhaka's air pollution causes 10,800 premature deaths and 6.5 million extra cases of sickness per annum, with an estimated loss of US\$200-800 million and a simultaneous congestion and accident loss of US\$520 million per annum (Haque and Hossain 2004). Average one-way commuting trip time to work in Bangkok is about 1 hour. All of these put into question the future sustainability of these cities. With this sort of caution in the air for recent years, regional governments are trying to address the challenge through a combination of increased investment in road stock and the development of complementary public transport systems, with clear emphasis on public transport systems in recent time. Successful embracing of transit-oriented urban transport development and BRT initiatives by upper income cities like Seoul and Taipei (Pucher et al. 2005; Chang and Sun 2004) have created motivation for similar approaches by the developing cities. Such public transport initiatives and planning approaches undertaken by a number of developing Asian cities are discussed below.

\section{China}

Sustainable transport and other development initiatives in the world's most populous and rapidly growing economy, China, are important for the stability of the Asian region and the world as a whole. Phenomenal economic growth during the last two decades has resulted in a significant increase in car ownership with associated congestion, air pollution, and enormous increases in gasoline consumption (Energy Foundation 2005; Chang 2005; ADB 2001). Rising oil prices have set the energy security and overall viability of Chinese cities on an unsustainable course. Under the circumstances, after a series of meetings and consultations with scientists, policy makers, business leaders, and analysts in China and the United States, 
a consortium of international organizations consisting of the David and Lucile Packard Foundation, the Energy Foundation, and the William and Flora Hewlett Foundation launched the China Sustainable Energy Program (CSEP) recently. The mission of the program is to assist in China's transition to a sustainable energy future by promoting energy efficiency and renewable energy. Transport is the primary consumer of the majority of the country's mostly-imported oil and has understandably drawn the attention of the program. The CSEP team developed the China Transportation Program Strategy with three clear goals, including the identification of BRT systems as means toward sustainable transportation systems. This initiative worked as a catalyst in generating interest among local politicians, mayors and decision makers. Since November 2001, as many as 14 Chinese cities have implemented a few BRT corridors or are in the process of implementing or are actively planning for a BRT system, as shown in the Table 1. Chang (2005) reported five key factors for BRT success in China: support from mayor(s); support from city councils; coordinated efforts of the new transportation commissions; comprehensive planning/design; and contributions of international teams. This shows the importance of strong political support and knowledgeable planning teams in an environment of well-integrated institutional setups for successful BRT planning initiatives. In some cities, bus manufacturers also are included in the development of BRT plans. This will ensure availability of needs-based, welldesigned buses and help the development of local industries for an emerging large BRT market in China and the region, ultimately reducing BRT installation costs and making the system even more viable financially.

It is striking to see so many successful BRT planning initiatives in China within only three to four year's time; BRT planning initiatives took decades in Latin American cities. The success was possible largely due to the catalytic initiatives from the CSEP group and a new generation of open-minded politicians in China, as well as China hosting the 2008 summer Olympic Games and World EXPO 2010. The total investment in urban transport for China's major cities is expected to reach the equivalent of US\$97 billion during the next five years, according to Chinese government figures (Wynne 2004).

\section{India}

India is the second most populous country in the world and home to about 35 cities with populations of more than 1 million. This is another Asian region with serious need for sustainable urban transport development. India has had favor- 


\section{Table 1. BRT Initiatives in Chinese Cities}

\begin{tabular}{|c|c|c|c|}
\hline Chinese City & $\begin{array}{l}\text { BRT Route } \\
\text { Planned }(\mathrm{km})\end{array}$ & $\begin{array}{l}\text { BRT Route } \\
\text { Implemented (km) }\end{array}$ & Agency \\
\hline Bejing & 300 & 15.8 & $\begin{array}{l}\text { Beijing Transportation Commission } \\
\text { \& Beijing municipal government }\end{array}$ \\
\hline Kunming & 73 & $\begin{array}{l}4.5 \text { ( fully } \\
\text { developed) and } 42 \\
\text { (partially developed) }\end{array}$ & $\begin{array}{l}\text { Kunming Urban Traffic Research Institute } \\
\text { (KUTRI) \& Kunming municipal } \\
\text { government }\end{array}$ \\
\hline Jinan & 12 & Partly in operation & $\begin{array}{l}\text { Jinan Urban Planning \& Design Institute, } \\
\text { Jinan Municipal Civil Engineering } \\
\text { Design Institute, and } \\
\text { China Academy of Urban Planning }\end{array}$ \\
\hline Xian & 48 & Planning stage & $\begin{array}{l}\text { Local university and municipal } \\
\text { government }\end{array}$ \\
\hline Chengdu & 28 & Planning stage & $\begin{array}{l}\text { Chengdu Institute of Urban Planning and } \\
\text { Design }\end{array}$ \\
\hline Chongqing & 15 & Planning stage & $\begin{array}{l}\text { Chongqing municipal government, } \\
\text { Chongqing Bus Company, and Chongqing } \\
\text { bus manufacturer }\end{array}$ \\
\hline Shanghai & 250 & Planning stage & Shanghai Urban Transport Bureau \\
\hline Tienjing & 145 & Planning stage & Municipal government \\
\hline Shenyang & $16\left(1^{\mathrm{st}}\right.$ phase $)$ & Planning stage & Municipal government \\
\hline Hangzhou & 28 & $\begin{array}{l}\text { Construction in } \\
\text { progress }\end{array}$ & Municipal government \\
\hline Guangzhou & $\begin{array}{l}\text { Planning } \\
\text { stage }\end{array}$ & Planning stage & Municipal government \& ITDP initiative \\
\hline
\end{tabular}

able rapid economic growth for more than a decade now. Increased income has paved the way for rapidly increasing levels of motor vehicle ownership and use, particularly in city areas. The emerging traffic situation has resulted in alarming levels of congestion, air pollution, noise, and traffic danger (Singh 2005). For most segments of the population, mobility and accessibility have declined with time (Pucher et al. 2005). Although the four mega-cities (Delhi, Mumbai, Kolkata and Chennai) have rail-based mass transit routes, the limited coverage of systems in these cities and generally unorganized, poor-quality, inadequate bus services (similar to other Indian cities) have resulted in an improper public transport supply in Indian cities. Commenting on the existing public transport supply, especially the bus system of small- and medium-sized Indian cities, Pucher et al. (2005) 
described them as old and poorly designed, inadequately maintained, dangerously overcrowded, undependable, and slow. Also, it is claimed that the systems require increasingly large subsidies, in spite of extremely high passenger volumes, due to inefficiency, outdated technology, incompetent management, corruption, overstaffing, and low worker productivity. However, it would be unfair not to mention that this poor situation emerges from the background of government-regulated and politically-sensitive low bus fare structures (less than US $2 \mathrm{c}$ per $\mathrm{km}$ ). Also, apart from Delhi, no significant efforts have been made recently to improve bus travel, which accounts for over 90 percent of all public transport use in India. With sharply increasing income and car ownership levels in Indian cities, it is important to preserve the competitive position of public transit (in this case, mainly bus) in order to be able to retain and/or increase the patronage through improved quality of service.

Recent major rail-based metro investments have been made in Kolkata and Delhi. The first phase of the Kolkata Metro, with a route length of $16.5 \mathrm{~km}$, was completed in 1995, and construction for a second expansion phase of $8.7 \mathrm{~km}$ is now under way at a cost of about USD\$200 million (Kolkata Metro webpage 2006). The Delhi Metro, with three routes and a combined length of $65 \mathrm{~km}$, was implemented at an estimated cost of USD $\$ 2.5$ billion and has taken a construction period of about 7.5 years (DMRC 2006). As pressure on central and local governments mounts from other cities for implementing similar metro projects, initiatives are coming up in a few cities for suitable transit options. Referring to the successful BRT system of Latin America, researchers (Wynne 2004; Leal and Bertini 2003; Pucher et al. 2005) suggested improved bus services like BRT systems for large and medium cities of India as a cost-effective, quicker, or more feasible solution.

In 2004, a pre-feasibility study of BRT system in Hyderabad was made by ITDP, and findings were presented by the ITDP team to the city's Chief Minister, who was nearly convinced of the value of implementing a BRT system (ITDP 2005). In spring 2005, however, after a round of staff changes, Hyderabad's urban development authorities made an interim recommendation to pursue a three-corridor, elevated rail system based on a proposal from the Delhi Metro Rail Corporation (DMRC). While not yet finalized, the system will be financed through a buildoperate-transfer scheme. The ITDP pre-feasibility study found that, for the same $\$ 1.1$ billion capital investment required for the 37-kilometer elevated metro, a 294-kilometer BRT system could be built. However, political support for the BRT concept waned when decision makers faced some difficult decisions regarding the 
right-of-way. Also, India's big cities are looking at ways to emulate the grand system like Delhi Metro, charmed by its image factor. However, during the opening of the third line of Delhi Metro, the prime minister of India determined that it was not necessary that all Indian states emulate the same model, as each place had different requirements. "There are other cheap transport alternatives available. The Central government will encourage all proven technologies that are economically feasible," the prime minister explained. Delhi has now taken up a BRT scheme of about $300 \mathrm{~km}$ throughout the capital, realizing that, due to costs and lengthy implementation time constraints, only limited extension of rail-based systems are feasible. Other cities actively considering suitable forms of mass transit options are Bangalore, Ahmedabad and Pune.

An international initiative such as in China seems necessary in India also. ITDP has already started the initiative, but it probably needs more collaborators, as adoption of BRT planning in Indian cities by agencies involved might not be as smooth as in the cases of China because of the numerous parties and frequently changing power bases in Indian politics. There is no shortage of planning and technical capability in India to carry forward the required initiatives, but the institutional integration and political support could be a barrier, and an international team may act as a bridging media.

\section{Bangkok}

In Bangkok, a wide array of generally uncoordinated government agencies claim to be dealing with transport; there are at least 27 agencies (mostly public) with responsibilities related to urban transport (Townsend 2001). Even after creation of the Office of the Commission for the Management of Land Transport (OCMLT) in 1992, with a mission to regulate the plans and programs of all transport agencies, there is still lacking an authoritative multi-modal transport master plan. Some of the transport planning, approving and operation agents include Bangkok Metropolitan Administration (BMA): the local city government; Office of the Commission for the Management of Land Traffic; Office of Transport and Traffic Policy and Planning (OTP); Bangkok Mass Transit System Company (BTSC), the company that operates the Skytrain; Bangkok Metro Company (BMCL), the company chosen to operate the subway; and Bangkok Mass Transit Authority (BMTA). While at all governmental levels public transport has been given adequate priority, planning and adoption of a certain public transport technologies is always a difficult job in this sort of multi-agent planning platform. 
In recent years, Bangkok's planning bodies have come up with three different types of mass transit systems for Bangkok. The Skytrain (23.5km route length), the first rail transit system in Bangkok, has been in operation since December 1999 and is known as Green Line. This elevated train is currently operated by BTSC. An underground subway is the second component of Bangkok's mass transit network and is known as Blue Line ( $20 \mathrm{~km}$ route length); it is currently operated by BMC (Zhi Liu 2005). These two systems were implemented at a cost of US\$60 million and US\$155 million per km, respectively. Another $247 \mathrm{~km}$ of subway is also planned, of which the $29 \mathrm{~km}$ Purple Line extension is already under construction, with a budget of US\$1260 million. A project budget allocation of US\$15 billion is also earmarked for the remainder of the metro extension. The third transit establishment planned is the Bangkok BRT system, which is a part of the greater mass transit project.

The central government played the key role in implementing the two train-based systems, while the local bodies and directorates are entrusted with the responsibility of the BRT system. BMA and OTP are in a "tug of war" with BRT planning and adoption. OTP planned 9 routes with a total coverage of $380 \mathrm{~km}$, while BMA planned 12 routes with a total coverage of $185 \mathrm{~km}$. They also differed on the issue of station facilities, with BMA favoring busy stations furnished with escalators and air-conditioning. The Bangkok governor, apparently a BRT enthusiast, pressed forward the BRT plan on the background that per-km BRT route costs only onesixteenth of elevated Skytrain cost. Efforts were underway for construction of the first two lines of BRT with a total route length of $35 \mathrm{~km}$. Being operated by different operators and physically separated, the integration of the system, especially integrating BRT with the train-based system, is considered a challenge that must be met for the better performance of the system.

Also, BRT implementation is about to face resistance from general motorists in the upcoming election-time opinion campaign, as predicted in the local newspaper. The reason behind this is that BRT will directly interact with local motorists, thus shrinking lanes available for motorists and affecting flows. Rail-based transit does not cause this sort of friction as it is mostly developed without influencing the flow of local motorists. This initial friction could be a significant impediment to the implementation of BRT. But Taipei's experiences (Chang and Sun 2004) show that BRT effectively saves travel time for both bus and non-bus trip makers, as travel speeds of buses as well as general traffic have increased significantly after the implementation of BRT. This is because interference between buses and other vehicles sharply decreases due to segregated lanes for BRT. Therefore, the 
BRT planning body needs to be resilient enough to absorb these initial criticisms and also emphasizes the need for promoting modal shift, especially from motorist groups, as soon as possible after BRT implementation so the road and the BRT system together create a balance in traffic demand sharing for the corridor. A few tools helping in this regard could be creating park-and-ride facilities and pedestrian and bike facilities and integrating different forms of public transport. Obviously, the role of the media and promotional activities can be significant in making the BRT system popular in a short period.

Transit planning efforts in Bangkok include the progress of two different transit systems in parallel: a BRT system with a per $\mathrm{km}$ cost of about USD $\$ 1.3$ million, and the subway metro (Purple Line) with a per $\mathrm{km}$ cost of about USD $\$ 43.4$ million. Although the difference in implementation costs between the two systems is staggering, BRT can match the capacity of the metro with adequate fleet composition and road furnishings (Wright 2005). With all the potential of BRT, its future in Bangkok hinges on the enthusiasm of the City's governor. Bangkok had exclusive bus lanes introduced in 1980, with a result of either bus travel times or car travel times, or both, being improved significantly (Marler 1982). But the gradually slackened enforcement and encroachment by sharply increasing car traffic made them virtually ineffective (except the contra-flow lanes) by late 1980s. This somehow has created a poor image for the Bangkok bus system, which the planned BRT system has to overcome for acceptance.

In recent months, developments around BRT initiatives also took a stormy turn, and the governor apparently gave up the BRT project, blaming the government for its lack of support and deliberate delays in granting an operating license. Traffic police also seem to have played a role in this by complaining that the loss of one lane to BRT would only worsen traffic congestion. This shows the necessity of strong political backing to ensure government collaboration, or at least no interference, and a professional planning team to overcome the doubts brought forward by different parties.

Comparing this setback to the successful ongoing BRT initiatives of Jakarta, it seems the governor of Jakarta has substantial control over the budget allocation required for the project. Jakarta allocated increasing funds of some Rp 140 billion (US\$14 million) in 2004 as compared to Rp 510 billion in 2005, and the governor has proposed Rp 876.70 billion for the four new busway corridor projects in 2006. The governor's team also has capitalized on the unsuccessful quest for a financier for the rail-based metro project (ITDP 2003). Recent ITDP studies $(2003,2005)$ in 
collaboration with the local universities also formed a basis for a sound BRT plan. The first BRT corridor of $12.9 \mathrm{~km}$ has experienced an increase in patrons from 20,000 per day to over 70,000 per day within less than two years of its operation. The Jakarta BRT team is now poised to see through a successful BRT network development.

\section{Kuala Lumpur}

Institutional fragmentation is commonly identified as a root cause of transport woes in Kuala Lumpur (KL), as in the case of Bangkok (Townsend 2001). There are a number of federal and local bodies, including 10 ministries, involved in transport related issues; however, there is no single agency to see through transport planning, regulation and implementation in KL (Saleh 2005). The lack of an institution with oversight and visions for the future of multi-modal transport development integrated with urban land use has encouraged individual public and private stakeholders to initiate uncoordinated transit projects. With a city governing body (including the mayor) appointed by the King, the local government lacks in strong political power. All this has led to a situation where the federal government and politicians, especially the Economic Planning Unit (EPU) of the prime minister, have emerged as the most influential forum for transportation planning initiatives in greater $\mathrm{KL}$.

The Klang Valley region (KV) went through rapid urbanization and sprawling development in the economic boom of the 1980s and 1990s. Increased income and sprawling land use development encouraged rapid motorization, and carbased traffic demand outpaced the expansion of expressways and toll roads. Under pressure from high traffic demand and congestion problems, a few railbased transit mega projects were initiated independently by politicians and private firms. As a result, the STAR LRT system, with two routes (combined length of $26 \mathrm{~km}$ ), was implemented at a cost of US\$1.4 billion during 1996-1998; the PUTRA LRT system, with route length of $29 \mathrm{~km}$, was implemented at a cost of US\$1.74 billion during 1995-1999; the KL Monorail, with a route length of $8.6 \mathrm{~km}$, was implemented at a cost of about US\$0.5 billion during 1996-2003; and two conventional commuting rail corridors of KTM were refurbished at an unknown cost. Although efforts were made to integrate these individual systems, only limited physical and almost no fare integration took place until 2004. Also, KL, a city of $243 \mathrm{sq} \mathrm{km}$ with sprawling development well beyond this boundary, has a network coverage of only six routes of mass transit, which seems inadequate; accordingly, the vast majority 
of the city and its outskirts are literally beyond transit coverage and linked only by bus services. Domination of the private-car-led congestion on the road and repeated failed attempts of bus service regulation, integration and improvement have resulted in a poor service image for the bus. With the dwindling patronage, bus operators suffered financial losses which further deteriorated service quality. As a result, transit modal share further declined to 16 percent in 2003 (BINAFIKIR 2005) from 19.7 percent in 1997, even after the introduction of three new railbased rapid transit systems during the early part of that period. Most transit investors ran into deep financial trouble. As a consequence, while traffic congestion has already become a perennial woe for $\mathrm{KL}$ residents, there is a looming prospect of doubling of the vehicle population in KV in next 7 to 10 years (NEAC 2003).

Although officially guided by a 1991 privatization master plan to rely on concessions granted to the private sector for infrastructure investments, the federal government played a supportive role through various means. One of these means was the provision of soft loans from the government to privately-financed projects (e.g., both LRT systems and several expressway projects). Under these conditions, there was an implicit guarantee against failure or "moral hazard" that has since caused problems in the wake of the economic crisis that began in 1997 (Townsend 2001). Therefore, the central government (not the local city councils) reacted to the above situation by forming a special task force for KV public transport under the prime minister's department, which guided a public transport restructuring plan (INSPAK) with the help of a private consultant study.

Accordingly, the federal government took up the responsibility of two LRT lines and a few major bus companies and, at the same time, undertook initiatives for restructuring KV's public transport system, with the objective of an integrated and efficient public transport system. A three-tier (regulating, asset owning and operation management) setup was planned to be introduced as a step towards the solution, of which only asset owning (SPNB) and operating (Rapid KL) management modules were put in place recently. SPNB, suggested to be a purely government-owned entity, has the responsibility of asset owning, funding and procurement. RapidKL, currently government-owned, has the responsibility of operation and asset maintenance. It has also the obligation to meet certain performance criteria based on key performance indices. In the first year of operation, RapidKL is going for a full-scale restructuring of the KV bus network without any substantial demand pattern study. However, it will acquire 800 new buses through SPNB, arranged by government funding for establishing the changed new network 
service. But the important institutional, planning and regulatory body is not commissioned yet, which might allow loopholes in the implementation of the INSPAK initiative. Also, this regulatory body is supposed to handle the planning, research and development initiatives, which are clearly currently missing.

It is evident that, even with all initiatives to have the public transport investment liability on the private sector, it has bounced back to the government's shoulder. Although the private road concessionaires are still surviving with the increased motorist patronage, the government is providing a nationwide fuel subsidy of around USD\$3.5 billion. The only way out for the government is increasing the public transport patronage through an integrated wide coverage network with good quality service. At the same time, it must look for a financially self-sustaining transit system. With a lower per $\mathrm{km}$ cost of implementation and financially selfsustaining experience, a BRT system can provide such wide-scale coverage without much financial liability on the government (Hook 2004; Ardila 2004). However, with the BRT initiatives in the two neighboring cities of Bangkok and Jakarta, the authority is clearly unmoved regarding any sort of BRT initiative. Clearly, a strong planning team and enthusiastic political will are missing, which were ingredients for successful BRT planning initiatives in Latin American cities. Although formation of the planned regulatory body and capacity building can fill the gap of the required planning team, the political will is unlikely to be generated from the currently appointed local government. The most probable political power source may come from the federal government, especially politicians working with the economic planning unit of the prime minister's department.

\section{Dhaka}

Dhaka, the capital of Bangladesh, is now a city of about 12 million people, and the population is expected to increase to 18.5 million in the year 2015 (MOC 2004; DITS 1994). In an ideal situation, roads and lanes would be constructed on 25 percent of the city's surface area, but in Dhaka it is only 8 percent (DCC 2002), as Dhaka grew from a provincial capital to a national capitol in an unplanned way. Dhaka is perhaps the only city of its size without a well-organized, properly scheduled bus system or any other mass transport system. The transport system in Dhaka is characterized by different types of modes, with both motorized transports (MT) \& non-motorized transport (NMT) using the same carriageway. The city transport system is now in a quagmire, with traffic congestion, delays, inadequate traffic management, conflict of jurisdictions, poor coordination among 
organizations, and increasing air pollution problems. The city's traffic problems have reached a crisis proportion-delays have tripled in the last three years and automobile-related air pollution has become a major health problem-such that these shortcomings seriously compromise the ability of the transport sector in the Dhaka metropolitan area to sustain economic growth and a reasonable quality of life (DTCB 2004). In many respects, the distribution of modal choices in Dhaka is unique among cities of comparable size in Asia. Almost 60 percent of the 8.5 million weekday person trips are walk trips, and about 19.2 percent are by rickshaw (tricycle). For the remaining 20 percent of trips on motorized modes, 1.4 percent use an auto-rickshaw (three-wheeler), 9.2 percent travel by bus, 3.1 percent travel by private car, and 6.7 percent travel by various other modes. In terms of passenger $\mathrm{km}$, the share of buses is 30.6 percent and those of rickshaw and walking are 21.7 percent and 17.7 percent, respectively (DTCB 2004). The high dependence on walking and rickshaw, which are both slow and typically best-suited for short trips on secondary roads, and a low dependence on buses in a city of 12 million people with an urban area of about 2,000 square $\mathrm{km}$ is a symptom of inefficient and ineffective transport operations as well as uncontrolled land-use.

Buses and minibuses are the main motorized public transport sub-mode within Dhaka. There are about 2,200 registered private buses and minibuses and 400 BRTC (Bangladesh Road Transport Corporation) buses. Recently, BRTC procured 50 modern EURO Engine Volvo double decker buses, which have a capacity of 160 (120 sitting and 40 standing). There are also 250 double decker buses of with a capacity of 103 ( 83 sitting and 20 standing). However, as buses negotiate mixed traffic including NMT, the operating speed of the buses is reduced to such an extent that NMT has almost become competitive in terms of speed in shorter trips, and a motorized three-wheeler is definitely advantageous for all trips. This situation has encouraged the growth of approximately 9,500 taxis, 10,000 auto rickshaws, and an unknown number of pedal rickshaws (in the range of 300,000 to 500,000), all of which cater to personalized services for passengers. A preliminary estimate of vehicular trip demand on the city's 18 major bus routes showed a demand range of 150,000 to 350,000 per day, with peak hour per direction demand in the range of 4,500 to 9,000 per hour (Hossain and Hossain 2003; Hossain et al. 2003). This sort of demand can be comfortably handled by any modern BRT system. Also, considering the affordability of residents and government financial constraints, BRT could be an ideal choice for Dhaka. 
Deteriorating traffic conditions have prompted several popular public campaigns to find urgent solutions. An important step taken by the government in was the formation of the Greater Dhaka Transport Planning and Coordination Board (DTCB) in 2001 to integrate activities, coordinate stakeholders, and formulate policy and planning options for the city. The city mayor is the chairman of DTCB board, which also includes members from 17 other public and private bodies, including the chairmen of three peripheral local municipalities. But the organization lacks capable manpower and other resources and, as such, has not been able to establish a foothold until recently. Due to this and competition among politicians to deal with mega projects, most of the mass transit planning proposals and initiatives revolve around the communication ministry and the prime minister's office, bypassing DTCB. During the tenure of earlier government (1996-2001), elevated metro rail project biddings were almost to the final stages. Although initially 32 firms expressed interest in that build-operate-transfer (BOT) bidding, at later stages the number decreased to only two, and a later change of government buried the whole initiative.

During the current government tenure, a number of proposals for rail-based metro have come up, which include both subway and elevated rail systems. No final decision has yet been made, and the current government tenure will end in October 2006. During the last three five-year periods, Bangladesh has seen the alternation of two political parties in power and, due to unhealthy political animosity, one party does not seem to appreciate the ideas adopted by the other party. This single issue has created risk for mega projects such as the urban metro, so the planning and implementation of any such project could extend over more than a five-year period. This highlights the importance of the window of opportunity for adopting and implementing a transit system in Dhaka, as mentioned in Ardila's study (2004). But to prepare for and grab that window of opportunity, there must be a professional setup with good institutional backup. DTCB could take that initiative, but, as mentioned earlier, the organization lacks adequate human resources, monetary support and motivation. With an adequate planning team setup, this situation is more suitable for adopting a BRT system, as it can be planned and implemented within the tenure of a government and possibly alleviate transport problems, thus even helping the government's political cause. Again, some kind of catalytic influence from international initiatives such as ITDP or the Energy Foundation Group in China and other countries may well help DTCB in rising to the cause of BRT development in Dhaka. 


\section{Lessons Learned}

BRT planning initiatives involve multiple agencies in a complex stakeholders' setup based on rationality and equity. Therefore, a BRT proposal is unlikely to generate any special or vested interest group to drag through the planning and adoption initiatives. More and more, Asian city authorities and politicians, especially in China, are realizing the potential and importance of BRT systems in low to middle income city situations. Still, a number of rail-based metro systems are in progress in many parts of Asia, where BRT could have been a much better alternative in terms of lower fares and financial liability for the fund constrained governments. Governments and city authorities should be realistic in selecting a mass transit technology, focusing their considerations on actual needs, implementation and financial issues rather than emphasizing the image factor. Public transport professionals and BRT enthusiasts should take the window of opportunity offered by changes in government, the funding crisis for metro projects, rising oil prices, and international events concerning national pride. A knowledgeable planning team backed by strong political support seems necessary for defending the doubts put forward by critics and making progress through the initial period of chaos and resistance created mainly by car lobbyists. Whereas political backing is a key ingredient for success in all BRT systems, this sort of support appears to be transient in Indian subcontinent. Required institutional, technical and management skills for BRT planning initiatives seem lacking in most Asian cities. International initiatives such as the Energy Foundation, the Hewlett and Packard Foundation in China, and ITDP initiatives in a number of cities should continue in the future years to help Asian cities develop sustainable transport initiatives using BRT technology.

\section{Acknowledgments}

The author would like to acknowledge helpful comments on an earlier version of this paper from two anonymous reviewers, as well as a few colleagues at MUST. Thanks are also due to on-going MUST-MIT collaboration through which Ardila's $\mathrm{PhD}$ thesis was made available to this author, which was the inspirational source for writing this paper. However, the author alone is responsible for any errors or omissions in the paper. 


\section{References}

Ardila, G. A. 2004. Transit planning in Curitiba and Bogotá. Roles in interaction, risk, and change. Ph D thesis, Department of Urban Studies and Planning, Massachusetts Institute of Technology.

Asian Development Bank (ADB), 2001. Assessing the impacts of transport/energy infrastructure on poverty reduction: Country case study of the People's Republic of China. Inception report (draft), available at ADB wesite www.adb. org.

Bangkok Post. 16 February 2005. www.bangkokpost.net. 2005.

BINAFIKIR. 2005. INSPAK: Restructuring Klang Valley's urban public transportation system. Presented at Public Transport Integration: A Special Workshop Organized by Rapid KL on September 13, 2005, Kuala Lumpur.

Chang, J. 2005. BRT Developments in China. Environment 2005 Conference,

Sustainable Transport and Cities: Improving Transit Systems, Pre-Conference Workshop, Abu Dhabi, UAE. Jan 29, 2005. http://www.cleanairnet.org/caiasia/1412/article-59535.html accessed 02/02/2006.

Chang, J., and J. Sun. 2004. Progress and prospect of BRT in Taiwan. Report prepared by National Taiwan University and THI Consultants Inc.

Delhi Metro Rail Corporation (DMRC), website www.delhimetrorail.com.

Dhaka City Corporation. 2002. Structure plan, master plan, and detailed area plan for Dhaka City. Volume-1, Dhaka, Bangladesh.

DITS.1994. Greater Dhaka Metropolitan Area integrated transport study, final report: Volume 1. Planning Commission and Department of Economic and Social Development, Government of Bangladesh, and United Nations Development Program.

Dhaka Transport Coordination Board (DTCB). 2004. Dhaka urban transport project 1998-2004. accessible at http://www.dtcb.gov.bd/dutp_backgroundmain. htm.

Energy Foundation. 2005. Studies on international fiscal policies for sustainable transportation: The China Sustainable Energy Program. March 2005.

Hindu. 13 December 2005. www.hinduonnet.com. 
Hindustan Times. 2 January 2006, website www.hindustantimes.com.

Hoque, M., and T. Hossain. 2004. Augmentation of mass transit mode in Dhaka, Bangladesh. Presented at CODATU XI in Bucharest, Romania. Available at www.codatu.org/francais/publications/ actes/conferences/codatu11/Papers/ hoque.pdf.

Hossain, M., and M. McDonald. 1998. Modelling the impacts of reducing the non-motorised traffic on urban corridors of developing cities, International Journal of Transportation Research, Part A. Elsevier Science Ltd, Vol.32, No. 4, pp. 247-260.

Hossain, S, and M. Hossain. 2003. Mass transit corridors identification and demand forecasting for Dhaka City using GIS. Proceedings of 2nd International Conference and Annual Paper Meet, Institution of Engineers, Dhaka, Bangladesh. July 2003.

Hossain, M., A. Ali, and M. Ansary. 2003. Study of mass transit options for major cities of Bangladesh. Ministry of Science, Information and Communication Technology, Government of the Peoples Republic of Bangladesh.

Hook, J.W. 2005. Institutional and regulatory options for bus rapid transit in developing countries: Lesson from international experience. Presented at the 2005 Annual Transportation Research Board Conference, January, 2005.

Hook, J.W. 2004. Bus rapid transit planning, institutional reform, and air quality: Lessons for Asia. Presented at the 2004 Better Air Quality Conference in Agra, India.

Institute for Transportation and Development Policy (ITDP). 2005. Pre-feasibility study for bus rapid transit Hyderabad. Accessible at http://www.itdp.org/ read/Hyderabad_BRT.pdf.

Institute for Transportation and Develeopment Policy (ITDP). 2003. Trans-Jakarta bus rapid transit system: Technical review. Accessible at http://www.itdp. org/read/.

Institute for Transportation and Develeopment Policy (ITDP). 2005. Making Trans-Jakarta a world class BRT system: Final recommendations of the Institute for Transportation and Development Policy. Accessible at http://www. itdp.org/read/. 
Lean, M., and R. Bertini. 2003. Bus Rapid Transit: An alternative for developing countries. Institute of Transportation Engineers, 2003 Annual Meeting, Seattle, Washington.

Jakarta Post. December 2005. www.thejakartapost.com.

Marler, N.W. 1982. The performance of high-flow bus lanes in Bangkok. TRL research report SR723, Transportation Reseach Laboratory, Berkshire, UK.

Ministry of Communications. 2004. National land transport policy. Government of Bangladesh.

Nation. February 2006. www.nationmultimedia.com.

National Economic Action Council (NEAC). 2003. National transport policy and strategy study, final report. Minconsult SDN BHD.

Patrick, D. S., and G.B. William. 2005. Innovative public-private partnership models for road pricing/BRT initiatives. Journal of Public Transportation, Vol. 8, No. 1.

Pucher, J., M.H. Kim, and J. Song. 2005. Public transport reforms in Seoul: Innovations motivated by funding crisis. Journal of Public Transportation, Vol.8, No.5.

Pucher, J., N., Korattyswaroopam, N. Mittal, and N. Ittyerah. 2005. Urban transport crisis in India. Transport Policy, Vol. 12, Issue 3, pp. 185-198.

Saleh, R.A. 2004. Urban transportation in Kuala Lumpur: The challenges ahead. Presentation at the National Multimodal Transport Conference 2004, Connecting the Multimodal Chain, Le Meridien Hotel, Kuala Lumpur.

Singh, S. K. 2005. Review of urban transportation in India. Journal of Public Transportation, Vol. 8, No. 1.

Townsend, C. 2001. Roads before rail: Development of expressways and mass transit in Bangkok and Kuala Lumpur. Proceedings of 9th World Congress on Transport Research, Seoul, South Korea.

UN ESCAP. 2005. Review of developments in transport in Asia and the Pacific 2005, available at http://www.unescap.org/ttdw/Publications/TPTS_pubs/ pub_2392/pub_2392_fulltext.pdf.

Wright, L. 2005. Sustainable transport: A sourcebook for policy-makers in developing cities, module $3 \mathrm{~b}$ : Bus rapid transit. ITDP web publication. Available at http://www.itdp.org/read/brtplanningguidedec04.pdf. 
Wright, L. 2001. Latin American busways: Moving people rather than cars. Natural Resources Forum, JNRF 25:2.

www.citymayors.com/features/largest_cities.html.

Wynne, G. 2004. Bogota's BRT achieves farebox coverage of operating costs. International transit. January 19, American Public Transportation Association. Accessible at: http://www.apta.com/services/intnatl/intfocus/bogota.cfm.

Wynne, G. 2004. Transit investments spur China market ahead of 2008 Beijing Olympics. Passenger Transport, August 23, http://www.apta.com/.

Zhi, L. 2005. The institutional and policy dimensions of mass transit system integration. Presented at Public Transport Integration: A Special Workshop, organized by Rapid KL on September 13, Kuala Lumpur.

\section{About The Author}

Moazzem Hossain (moazzem@must.edu.my) is an Associate Professor of Transportation and Logistics at the Malaysia University of Science and Technology (MUST). His research and consultation interests include transport system simulation, public transport operation, and non-motorized transport. He has published extensively in various journals and conference proceedings and has developed a mixed traffic network simulation model, MIXNETSIM, for simulating urban road network with heterogeneous traffic. The simulation model has been applied in various developing countries, especially in Bangladesh, for simulation of bus lane and at-grade LRT operation under mixed traffic situations of developing cities. 